\title{
The role of ammonia in sulfuric acid ion induced nucleation
}

\author{
I. K. Ortega, T. Kurtén, H. Vehkamäki, and M. Kulmala \\ Division of Atmospheric Sciences, Department of Physical Sciences, P.O. Box 64, FI-00014 University of Helsinki, Finland
}

Received: 9 January 2008 - Published in Atmos. Chem. Phys. Discuss.: 17 March 2008

Revised: 20 May 2008 - Accepted: 20 May 2008 - Published: 5 June 2008

\begin{abstract}
We have developed a new multi-step strategy for quantum chemical calculations on atmospherically relevant cluster structures that makes calculation for large clusters affordable with a good accuracy-to-computational effort ratio. We have applied this strategy to evaluate the relevance of ternary ion induced nucleation; we have also performed calculations for neutral ternary nucleation for comparison. The results for neutral ternary nucleation agree with previous results, and confirm the important role of ammonia in enhancing the growth of sulfuric acid clusters. On the other hand, we have found that ammonia does not enhance the growth of ionic sulfuric acid clusters. The results also confirm that ioninduced nucleation is a barrierless process at high altitudes, but at ground level there exists a barrier due to the presence of a local minimum on the free energy surface.
\end{abstract}

\section{Introduction}

Aerosols are ubiquitous in the Earth's lower atmosphere. They affect human health, visibility, atmospheric chemistry, and climate. Aerosols influence climate directly by scattering and absorbing radiation, and indirectly by acting as cloud condensation nuclei and affecting cloud properties. Gas-toparticle nucleation is an important source of new aerosol particles in the Earth's atmosphere (Kulmala et al., 2004). A strong correlation has been observed between new-particle formation and sulfuric acid concentrations (Weber et al., 1996, Weber et al., 1997, Kulmala et al., 2006, Sihto et al., 2006, Riipinen et al., 2007). Water is also implicated in the formation of new particles because it is abundant, and because it significantly lowers the saturation vapor pressure of sulfuric acid. However, in many cases the observed rates of particle formation greatly exceed those expected on the

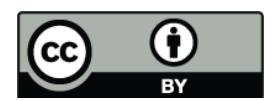

Correspondence to: I. K. Ortega (ismael.ortegacolomer@helsinki.fi) basis of binary homogeneous sulfuric acid-water nucleation. Although several alternative processes have been proposed, the most realistic candidates are (a) homogeneous ternary water-sulfuric acid-ammonia nucleation, (b) ion-induced nucleation of binary or ternary inorganic vapours or of organic vapours and (c) barrierless homogeneous nucleation of, for example, iodine species (Kulmala et al., 2000; Kulmala 2003; Lovejoy et al., 2004).

Atmospheric new-particle formation might actually be a two-step process (Kulmala et al., 2000). The first step would be the nucleation process itself, producing atmospheric (neutral or ion) clusters. The second step would be the activation of clusters for growth (Kulmala et al., 2006). The first step could also include the recombination of atmospheric ion clusters.

In the first step, ternary homogenous nucleation seems to be thermodynamically possible in many atmospheric conditions (Anttila et al., 2005). Also ion-induced nucleation has been shown to contribute to observed particle formation events, for example in boreal forest regions (Laakso et al., 2006), though its total contribution to new-particle formation events on the annual scale is very likely to be less than $10 \%$ even if ion recombination is included (Kulmala et al., 2007) The precise identities of the participating ionic and neutral molecular species are as yet unknown. Cluster properties predicted by bulk thermodynamics are not valid during the atmospheric nucleation processes. Therefore, quantum chemical studies are needed to find reliable formation pathways for small clusters.

Among the proposed mechanisms, one of the less studied is ion-induced ternary nucleation. As far as we know, there is only one work by Kurtén et al. (2007a) dealing with the hydrogensulfate ion - ammonia system; in their work the authors have performed quantum chemical calculations at the MP2/aug-cc-pV(T+d)Z level (with corrections at the MP4/aug-cc-pV(D+d)Z level) on clusters with one sulfuric acid or hydrogensulfate ion and one ammonia.

Published by Copernicus Publications on behalf of the European Geosciences Union. 
In the present work, we have studied clusters containing one hydrogensulfate ion, one ammonia and up to three sulfuric acid molecules. To evaluate the role of ammonia in the clusters, we also have performed calculation for neutral clusters containing up to four sulfuric acid molecules with and without ammonia, and for charged clusters without ammonia. In order to make affordable the calculation for the largest clusters investigated in this study, a new theoretical strategy has been developed.

\section{Computational details}

Our calculations were performed using a systematic multistep method. The initial guess geometries were chosen using chemical intuition and, when possible, geometries from earlier studies (Kurtén et al., 2007a, b, c; Torpo et al., 2007; Lovejoy et al., 2004). The SPARTAN program (Wavefunction Inc., 2006) was then used to pre-optimize these structures. Once a large enough set of geometries was sampled, the more stable isomers (usually between 6 and 10) were optimized using the SIESTA program (Soler et al., 2002), which is based on DFT, uses linear combinations of atomic orbitals as wave functions, and norm conserving pseudopotentials for the core electrons. Preliminary calculations were performed to choose the best functional and basis set for this system. The gradient corrected BLYP functional (Miehlich et al., 1989) gave the best agreement with experimental molecular geometries, and the double- $\zeta$ polarized (DZP) functions were found to be the best compromise between accuracy and computational effort. Vibrational harmonic frequencies were also calculated using this program, and were used to estimate the entropy and thermal contributions to the enthalpy and Gibbs free energy of the clusters.

Finally, the optimized structures from the SIESTA program were used to perform single point energy calculations using the TURBOMOLE program (Ahlrichs et al., 1989) with the Resolution of Identity- Coupled Cluster Single and Doubles method (RI-CC2) (Hättig et al., 2000). The chosen basis set was aug-cc-pV(T+d)Z (Dunning Jr., et al., 2001), which is identical to aug-cc-pVTZ for hydrogen, oxygen and nitrogen atoms, and contains one extra set of $d$-orbitals for the sulfur atoms. The choice of basis set was based on previous results (Kurtén et al., 2007c) which indicate that basis-set effects beyond the aug-cc-pV(T+d)Z level are, at least with the MP2 method, too small (under $0.5 \mathrm{kcal} / \mathrm{mol}$ in terms of binding energy per molecule) to justify the computational effort of using e.g. a quadruple- $\zeta$ basis.

\subsection{Thermodynamics calculation}

We can approximate the total free energy of these systems as a sum of terms involving translational, rotational, vibrational and electronic states. We have used the rigid-rotor harmonicoscillator (RRHO) approximation, within which standard an- alytical formulae are available (Jensen, 1998) for the different contributions to the thermal entropies and enthalpies:

$$
\begin{aligned}
& H_{\text {trans }}=\frac{5}{2} R T \\
& H_{\text {rot }}=\frac{3}{2} R T \\
& H_{\text {vib }}=R \sum_{i=1}^{3 N-6}\left(\frac{h v_{i}}{2 k}+\frac{h v_{i}}{k} \frac{1}{e^{h v_{i} / k T}-1}\right) \\
& S_{\text {trans }}=\frac{5}{2} R+R \ln \left(\frac{V}{N_{A}}\left(\frac{2 \pi M k T}{h^{2}}\right)^{3 / 2}\right) \\
& S_{\text {rot }}=R\left(\frac{3}{2}+\ln \left(\frac{\sqrt{\pi}}{\sigma}\left(\frac{8 \pi^{2} k T}{h^{2}}\right)^{3 / 2} \sqrt{I_{1} I_{2} I_{3}}\right)\right) \\
& S_{\text {vib }}=R \sum_{i=1}^{3 N-6}\left(\frac{h v_{i}}{k T} \frac{1}{e^{h v_{i} / k T}-1}-\ln \left(1-e^{-h v_{i} / k T}\right)\right) \\
& G_{\text {therm }}(T, P)=H_{\text {therm }}(T)-T S(T, P) \\
& G(T, P)=G_{\text {therm }}(T, P)+E_{0}
\end{aligned}
$$

In these equations $H, S$ and $G$ are the enthalpy, entropy and free energy respectively, and the subscripts correspond to translational, rotational, vibrational and thermal, $R$ is the ideal gas constant, $T$ is the temperature, $h$ is the Planck constant, $k$ is the Boltzmann constant, $v_{i}$ are the harmonic frequencies calculated by SIESTA( where the notation index $i$ runs from 1 to total number of frequencies, $3 \mathrm{~N}-6$, where $\mathrm{N}$ is the number of atoms), $\mathrm{M}$ is the molecule mass, $V$ is the molar volume, $N_{A}$ is the Avogadro number, $I_{1,2,3}$ are the moments of inertia, calculated from SIESTA optimized geometries, $\sigma$ is the order of the rotational subgroup in the molecular point group (i.e. the number of proper symmetry operations) and $E_{0}$ is the electronic energy, which is calculated by TURBOMOLE.

It should be noted that though the free energies computed using the RRHO approximation are not quantitatively accurate (Kurtén et al., 2007a, Kathmann et al., 2007), they can be used quite reliably to qualitatively compare, e.g., different nucleation pathways, as the effects of anharmonicity tend to cancel out when differences in free energies are calculated.

Using as input for these equations the frequencies and moments of inertia obtained from the SIESTA program and the electronic energy calculated with TURBOMOLE, we can calculate enthalpy $H$, entropy $S$ and Gibbs free energy $G$ for a given temperature $T$ and pressure $P$. Using this data we can then calculate the clusters' formation free energies from the isolated molecules using the general expression:

$$
\begin{aligned}
& \Delta G(T, P)_{\text {for }}=G(T, P)_{\text {cluster }}-\left(n_{S A} G(T, P)_{S A}\right. \\
& \left.+n_{A m} G(T, P)_{A m}+n_{\text {ion }} G(T, P)_{\text {ion }}\right)
\end{aligned}
$$


Table 1. Enthalpy change $\Delta H$ (in units of $\mathrm{kcal} / \mathrm{mol}$ ) comparison between experimental and calculated values.

\begin{tabular}{lll}
\hline Reaction & $\begin{array}{l}\Delta H 295 \mathrm{~K} \\
\text { (Lovejoy et al., 2004) }\end{array}$ & $\Delta H$ 295K Calculated \\
\hline $\mathrm{H}_{2} \mathrm{SO}_{4}+\mathrm{HSO}_{4}^{-} \rightarrow \mathrm{H}_{2} \mathrm{SO}_{4} \cdot \mathrm{HSO}_{4}^{-}$ & -41.8 & -49.2 \\
$\mathrm{H}_{2} \mathrm{SO}_{4}+\mathrm{H}_{2} \mathrm{SO}_{4} \cdot \mathrm{HSO}_{4}^{-} \rightarrow\left(\mathrm{H}_{2} \mathrm{SO}_{4}\right)_{2} \cdot \mathrm{HSO}_{4}^{-}$ & -27.4 & -26.8 \\
$\mathrm{H}_{2} \mathrm{SO}_{4}+\left(\mathrm{H}_{2} \mathrm{SO}_{4}\right)_{2} \cdot \mathrm{HSO}_{4}^{-} \rightarrow\left(\mathrm{H}_{2} \mathrm{SO}_{4}\right)_{3} \cdot \mathrm{HSO}_{4}^{-}$ & -23.8 & -23.2 \\
\hline
\end{tabular}

Table 2. The Gibbs formation free energies (relative to molecules with partial pressure $1 \mathrm{~atm}$ ) in units of $\mathrm{kcal} / \mathrm{mol}$ at $298,265 \mathrm{and} 242 \mathrm{~K}$ are listed as a function of the number of total sulfuric acid molecules and hydrogensulfate ions in the clusters.

\begin{tabular}{lllll}
\hline $\mathrm{n} \mathrm{SA}$ & $\left(\mathrm{H}_{2} \mathrm{SO}_{4}\right)_{n}$ & $\left(\mathrm{H}_{2} \mathrm{SO}_{4}\right)_{n} \cdot \mathrm{NH}_{3}$ & \multicolumn{3}{c}{$\left(\mathrm{H}_{2} \mathrm{SO}_{4}\right)_{n-1} \cdot\left(\mathrm{HSO}_{4}^{-}\right)$} & $\left(\mathrm{H}_{2} \mathrm{SO}_{4}\right)_{n-1} \cdot\left(\mathrm{HSO}_{4}^{-}\right) \cdot \mathrm{NH}_{3}$ \\
\hline \multicolumn{5}{c}{$\mathbf{2 9 8} \mathbf{K}$} \\
\hline $\mathbf{2}$ & -8.84 & -19.15 & -34.52 & -33.05 \\
$\mathbf{4}$ & -9.66 & -28.07 & -52.71 & -66.52 \\
& -17.73 & -39.23 & -60.57 & -70.20 \\
\hline $\mathbf{2}$ & -9.65 & -21.82 & -36.14 & $\mathbf{2 6 5 ~ K}$ \\
$\mathbf{3}$ & -12.54 & -32.11 & -55.28 & -35.78 \\
$\mathbf{4}$ & -21.50 & -43.51 & -62.62 & -69.79 \\
\hline & & & $\mathbf{2 4 2} \mathbf{K}$ & -75.89 \\
\hline $\mathbf{2}$ & -10.21 & -23.67 & -37.26 & -37.68 \\
$\mathbf{3}$ & -14.55 & -34.93 & -57.07 & -72.07 \\
$\mathbf{4}$ & -24.12 & -46.50 & -67.78 & -79.86 \\
\hline
\end{tabular}

Where $n$ is the number of molecules of each species in the cluster (subscript SA corresponds to sulfuric acid, Am to ammonia and ion to hydrogensulfate ion).

Equation (9) gives the formation free energies at some standard conditions (usually $P_{0}=1 \mathrm{~atm}$ and $T=298 \mathrm{~K}$ ), but to obtain a realistic picture of the free energies in atmospheric conditions, we have to take into account the relative concentration of each molecular species in atmosphere. This is done via the law of mass action, with which the calculated free energies can be converted to ambient conditions in terms of the partial pressures of each compound:

$$
\begin{aligned}
& \Delta G\left(P_{S A}, P_{A m}, P_{\text {ion }}\right)=\Delta G\left(P_{0}\right)+n_{S A} R T \ln \left[\frac{P_{0}}{P_{s a}}\right] \\
& +n_{A m} R T \ln \left[\frac{P_{0}}{P_{A m}}\right]+n_{\text {ion }} R T \ln \left[\frac{P_{0}}{P_{\text {ion }}}\right]
\end{aligned}
$$

Where $\Delta G\left(P_{0}\right)$ is the free energy at standard pressure, $n_{S A}$, $n_{A m}$ and $n_{\text {ion }}$, are the number of sulfuric acid, ammonia and hydrogensulfate ion molecules in the cluster and $P_{S A}, P_{A m}$ and $P_{\text {ion }}$ are the actual partial pressures of sulfuric acid, ammonia and hydrogensulfate ion at atmospheric conditions.

\subsection{Methodology performance}

In order to check the performance of our methodology we have calculated enthalpy changes $\Delta H$ at $295 \mathrm{~K}$ for the reactions $\left(\mathrm{H}_{2} \mathrm{SO}_{4}\right)_{a} \cdot \mathrm{HSO}_{4}^{-}+\mathrm{H}_{2} \mathrm{SO}_{4} \rightarrow\left(\mathrm{H}_{2} \mathrm{SO}_{4}\right)_{a+1} \cdot \mathrm{HSO}_{4}^{-}$with $\mathrm{a}=0-2$, and compared the results with experimental values given by Lovejoy et al. (2004). The results of the comparison are shown in Table 1.

As we can see in the table, our multi-step method overestimates the value of $\Delta H$ for the first sulfuric acid addition by $7.4 \mathrm{kcal} / \mathrm{mol}$. This difference is mainly due to the high anharmonicity of the $\mathrm{HSO}_{4}^{-}$ion, and specifically to the presence of one internal rotation which is incorrectly modeled as a lowfrequency vibration, see, e.g., Kurtén et al. (2007a) for details. As mentioned in the previous section, we are using the harmonic oscillator approximation to obtain the thermodynamic properties of the system, and this particular molecule is not well described with this approximation. We also can see in the table that the difference between calculated and experimental $\Delta H$ values is much lower $(-0.6 \mathrm{kcal} / \mathrm{mol})$ for the reactions not involving the isolated ion, where the participating species are less anharmonic. It should be noted that the error due to the anharmonicity of the hydrogensulfate ion is 

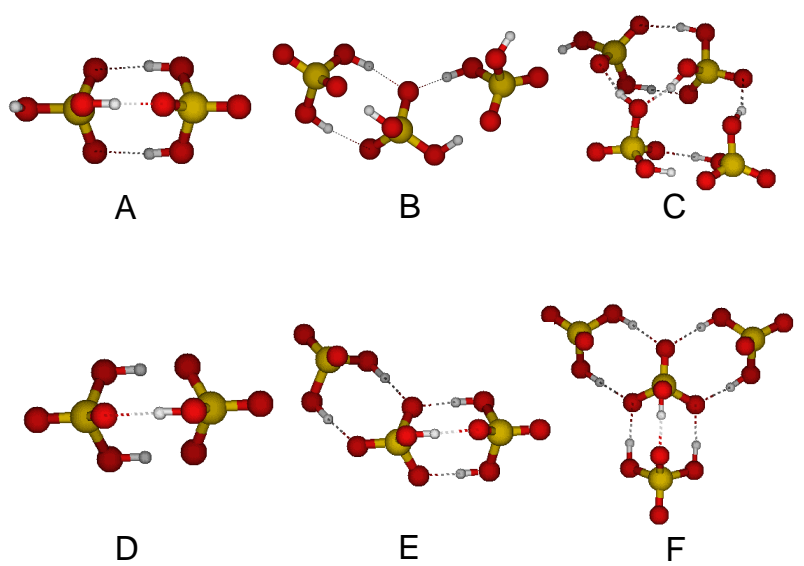

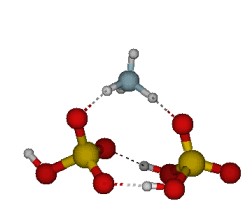

G

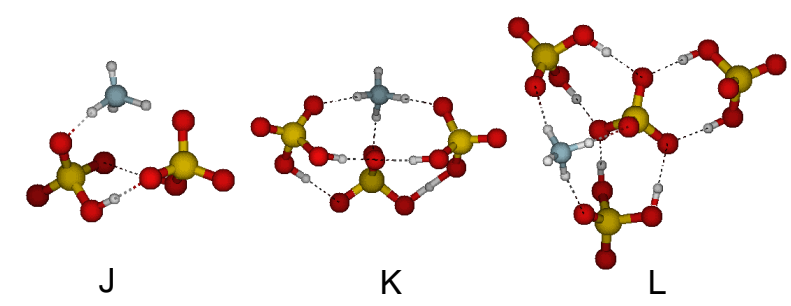

Fig. 1. The most stable clusters:

(A) $\left(\mathrm{H}_{2} \mathrm{SO}_{4}\right)_{2}$,

(B) $\left(\mathrm{H}_{2} \mathrm{SO}_{4}\right)_{3}$,

(C) $\left(\mathrm{H}_{2} \mathrm{SO}_{4}\right)_{4}$,

(D) $\left(\mathrm{H}_{2} \mathrm{SO}_{4}\right) \cdot\left(\mathrm{HSO}_{4}^{-}\right)$,

(E) $\left(\mathrm{H}_{2} \mathrm{SO}_{4}\right)_{2} \cdot\left(\mathrm{HSO}_{4}^{-}\right)$,

(F) $\left(\mathrm{H}_{2} \mathrm{SO}_{4}\right)_{3} \cdot\left(\mathrm{HSO}_{4}^{-}\right)$,

(G) $\left(\mathrm{H}_{2} \mathrm{SO}_{4}\right)_{2} \cdot \mathrm{NH}_{3}$,

(H) $\left(\mathrm{H}_{2} \mathrm{SO}_{4}\right)_{3} \cdot \mathrm{NH}_{3}$,

(I) $\left(\mathrm{H}_{2} \mathrm{SO}_{4}\right)_{4} \cdot \mathrm{NH}_{3}$,

(J) $\left(\mathrm{H}_{2} \mathrm{SO}_{4}\right) \cdot\left(\mathrm{HSO}_{4}^{-}\right) \cdot \mathrm{NH}_{3}$,

(K) $\left(\mathrm{H}_{2} \mathrm{SO}_{4}\right)_{2} \cdot\left(\mathrm{HSO}_{4}^{-}\right) \cdot \mathrm{NH}_{3}$,

(L) $\left(\mathrm{H}_{2} \mathrm{SO}_{4}\right)_{3} \cdot\left(\mathrm{HSO}_{4}^{-}\right) \cdot \mathrm{NH}_{3}$.

White atoms are hydrogen, the red ones are oxygen, the yellow ones sulfurs and the blue atoms nitrogen.

a constant factor, and does not affect the intercomparison of different ion-induced nucleation mechanisms. It does, however, somewhat decrease the reliability of the comparison of neutral and ion-induced mechanisms to each other.

It can be seen that the methodology applied in this paper yields, in general, values that are in good agreement with experimental results. In the case of highly anharmonic molecules the results deviate more form the experimental values, but the difference is comparable to other quantum chemistry methods used to study these systems.

\subsection{Results and discussion}

Modeling the hydration of sulfuric acid - ammonia clusters is problematic. In typical atmospheric conditions, two-acid clusters can be bound to seven or eight water molecules according to previous results (Kurtén et al., 2007c). The addition of water molecules to the cluster increases the computational effort in two ways. First, increasing the size of the system results in an increment in the CPU time and memory needed for the calculations, and second, the number of possible conformers increases combinatorially with the number of molecules present in the cluster. Also, as the degree of water-water bonding grows, the harmonic oscillator and rigid rotor approximation that we have assumed become less reliable. Previous results (Kurtén et al., 2007b, c; Ianni and Bandy, 1999) indicates that the binding of ammonia to the clusters is only weakly dependent on the water content. The effect is also to some extent systematic: the addition of water molecules tends to somewhat decrease the binding of ammonia to the cluster. Thus, the binding of a few water molecules to the cluster is unlikely to significantly disrupt the bonding pattern of the sulfuric acid - ammonia cluster. As the objective of this work was to study large clusters like $\left(\mathrm{H}_{2} \mathrm{SO}_{4}\right)_{4} \cdot \mathrm{NH}_{3}$, which already requires a quite significant computational effort, we have only considered dehydrated clusters. Hydration will certainly change the quantitative results (e.g., the free energy curves), but the qualitative conclusions regarding, e.g., the role of ammonia or the existence of a barrier for ion-induced nucleation are expected to be reliable despite the absence of water molecules in our simulations.

Figure 1 shows the structure of the most stable configuration for each cluster, obtained using the SIESTA program with the BLYP functional and the DZP basis set, sometimes the energy difference between the two most stable clusters was below $1 \mathrm{kcal} / \mathrm{mol}$. The structures have been drawn using the MOLDEN 3.8 visualization package (Schaftenaar et al., 2000). Table 2 list the obtained $\Delta G_{\text {cluster values (with }}$ respect to formation from free molecules) at 298, 265 and $242 \mathrm{~K}$ and monomer pressures of $1 \mathrm{~atm}$, as a function of total number of sulfuric acid molecules and $\mathrm{HSO}_{4}^{-}$ions in the cluster. The calculation of the thermal contributions to the free energies has been described in the previous section. It can be seen from Table 2 that, as expected from previous studies (Torpo et al., 2007; Nadykto and Yu, 2007), the presence of ammonia in the neutral clusters is favored thermodynamically in comparison with pure sulfuric acid clusters: the free energy for complexation is more negative in clusters with ammonia. From the table we can also see that this free energy lowering at first becomes more important as the number of sulfuric acids increases. However, the magnitude of the effect for the $\left(\mathrm{H}_{2} \mathrm{SO}_{4}\right)_{3} \cdot \mathrm{NH}_{3}+\mathrm{H}_{2} \mathrm{SO}_{4} \rightarrow\left(\mathrm{H}_{2} \mathrm{SO}_{4}\right)_{4} \cdot \mathrm{NH}_{3}$ reaction is less than that for the $\left(\mathrm{H}_{2} \mathrm{SO}_{4}\right)_{2} \cdot \mathrm{NH}_{3}+\mathrm{H}_{2} \mathrm{SO}_{4} \rightarrow$ $\left(\mathrm{H}_{2} \mathrm{SO}_{4}\right)_{3} \cdot \mathrm{NH}_{3}$ reaction. By comparing the ionic and neutral clusters, we can see that the presence of the hydrogensulfate 
Table 3. The temperature and vapor pressure values chosen to represent different conditions.

\begin{tabular}{llll}
\hline Variable & $\Delta \mathrm{G}_{1}$ conditions & $\Delta \mathrm{G}_{2}$ conditions & $\Delta \mathrm{G}_{3}$ conditions \\
\hline & Upper troposphere & Mid-troposphere & Ground level \\
Temperature $(\mathrm{K})$ & 242 & 265 & 298 \\
$\mathrm{P}_{A M}\left(\mathrm{~cm}^{-3}\right)$ & $4.246 \cdot 10^{8}$ & $2.769 \cdot 10^{10}$ & $2.769 \cdot 10^{10}$ \\
$\mathrm{P}_{S A}\left(\mathrm{~cm}^{-3}\right)$ & $2.000 \cdot 10^{7}$ & $1.000 \cdot 10^{7}$ & $1.000 \cdot 10^{6}$ \\
$\mathrm{P}_{\text {ion }}\left(\mathrm{cm}^{-3}\right)$ & $1.000 \cdot 10^{3}$ & $1.000 \cdot 10^{3}$ & $1.000 \cdot 10^{2}$ \\
\hline
\end{tabular}
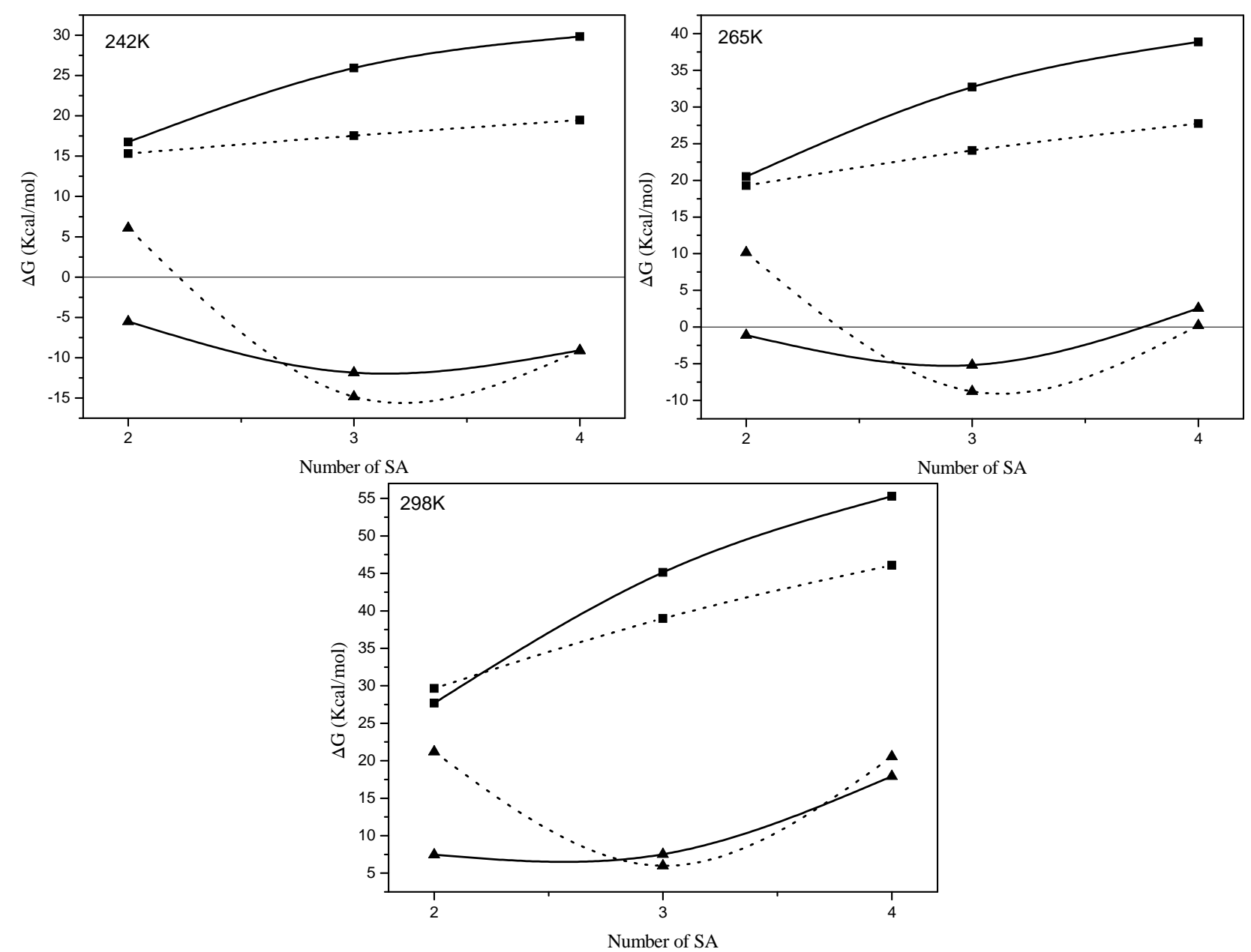

Fig. 2. Gibs free energy of formation in function of total number of sulfuric acids in the cluster (neutral and charged), broken lines represent cluster with ammonia, solid lines represent cluster without ammonia, squares represent neutral clusters, triangles represent charged clusters. Upper panel: corresponds to upper troposphere $\left(\Delta G_{1}\right)$ conditions, Middle panel corresponds to mid-troposphere $\left(\Delta G_{2}\right)$ conditions and Lower panel: corresponds to ground level $\left(\Delta G_{3}\right)$ conditions, Table 3 lists the temperature and vapor pressures used.

ion is even more favored than the presence ammonia, as the complexation free energy is more negative for ionic clusters than for neutral ammonia-sulfuric acid clusters. In this case, the magnitude of the lowering effect reaches a maximum for the $\left(\mathrm{H}_{2} \mathrm{SO}_{4}\right)_{2} \cdot \mathrm{HSO}_{4}^{-}$cluster. Finally, we can see that the presence of ammonia in the ionic clusters is not fa- vorable up to the $\left(\mathrm{H}_{2} \mathrm{SO}_{4}\right) \cdot \mathrm{HSO}_{4}^{-} \cdot \mathrm{NH}_{3}$ cluster, but is slightly favorable for larger clusters. If we again consider the magnitude of this energy lowering, it reaches a maximum for the $\left(\mathrm{H}_{2} \mathrm{SO}_{4}\right)_{2} \cdot \mathrm{HSO}_{4}^{-} \cdot \mathrm{NH}_{3}$ cluster. The results concerning neutral clusters are in good agreement with previous studies (Torpo et al., 2007). 
Table 4. The formation free energies for various cluster at atmospheric conditions listed in Table 3.

\begin{tabular}{lrrr}
\hline Cluster & Upper trop. $\Delta G_{1}$ & Mid-trop. $\Delta G_{2}$ & Ground level $\Delta G_{3}$ \\
\hline$\left(\mathrm{H}_{2} \mathrm{SO}_{4}\right)_{2}$ & 16.76 & 20.52 & 27.68 \\
$\left(\mathrm{H}_{2} \mathrm{SO}_{4}\right)_{3}$ & 25.92 & 32.72 & 45.12 \\
$\left(\mathrm{H}_{2} \mathrm{SO}_{4}\right)_{4}$ & 29.83 & 38.85 & 55.30 \\
$\left(\mathrm{H}_{2} \mathrm{SO}_{4}\right)_{2} \cdot \mathrm{NH}_{3}$ & 15.32 & 19.27 & 29.64 \\
$\left(\mathrm{H}_{2} \mathrm{SO}_{4}\right)_{3} \cdot \mathrm{NH}_{3}$ & 17.55 & 2406 & 38.98 \\
$\left(\mathrm{H}_{2} \mathrm{SO}_{4}\right)_{4} \cdot \mathrm{NH}_{3}$ & 19.47 & 27.75 & 46.08 \\
$\left(\mathrm{H}_{2} \mathrm{SO}_{4}\right)_{1} \cdot\left(\mathrm{HSO}_{4}^{-}\right)$ & -5.52 & -1.11 & 7.45 \\
$\left(\mathrm{H}_{2} \mathrm{SO}_{4}\right)_{2} \cdot\left(\mathrm{HSO}_{4}^{-}\right)$ & -11.85 & -5.17 & 7.52 \\
$\left(\mathrm{H}_{2} \mathrm{SO}_{4}\right)_{3} \cdot\left(\mathrm{HSO}_{4}^{-}\right)$ & -9.07 & 2.57 & 1792 \\
$\left(\mathrm{H}_{2} \mathrm{SO}_{4}\right)_{1} \cdot\left(\mathrm{HSO}_{4}^{-}\right) \cdot \mathrm{NH}_{3}$ & 6.08 & 10.16 & 21.19 \\
$\left(\mathrm{H}_{2} \mathrm{SO}_{4}\right)_{2} \cdot\left(\mathrm{HSO}_{4}^{-}\right) \cdot \mathrm{NH}_{3}$ & -14.83 & -8.77 & 5.98 \\
$\left(\mathrm{H}_{2} \mathrm{SO}_{4}\right)_{3} \cdot\left(\mathrm{HSO}_{4}^{-}\right) \cdot \mathrm{NH}_{3}$ & -9.14 & 0.21 & 20.56 \\
\hline
\end{tabular}

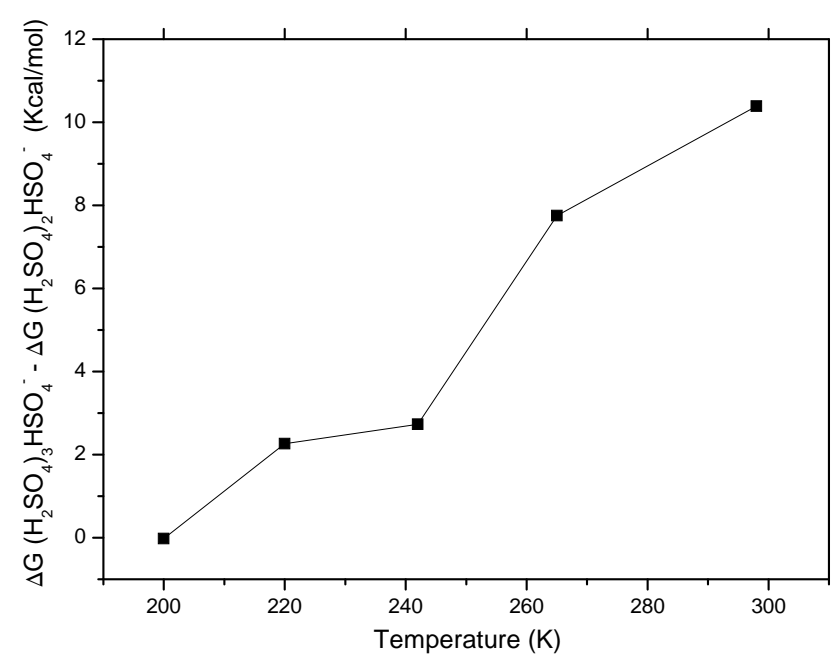

Fig. 3. Free energy difference between three and four sulfuric acid ionic clusters, for $220 \mathrm{~K}$ and $200 \mathrm{~K}$ points we used the same concentrations as given for $\Delta G_{1}$ in Table 3 .

The free energies for complexation at standard conditions listed in Table 2 can not be directly used to explain the nucleation-enhancing effect of, e.g., ammonia or the hydrogensulfate ion. The cluster formation free energy also depends on the relative atmospheric concentration of each molecular species in the atmosphere through the law of mass action as shown in Eq. (10). We have used the methodology explained in the previous section to estimate formation free energies for three representative atmospheric conditions (listed in Table 3). The first set of parameters has been chosen to fit the conditions found at high altitude (upper troposphere), with a low temperature, low concentration of ammonia and high concentration of ions. The second set corresponds to a mid-troposphere situation with more ammonia and a higher temperature, and the last corresponds to low altitude (ground level) conditions, with a higher temperature and a lower ion concentration.
The formation $\Delta G$ calculated for these conditions are listed in Table 4 and plotted in Fig. 2. Recently, Du et al. (2007) have presented a $\Delta G$ plot for water clusters, but as far as we know this is the first time that a formation free energy curve for sulfuric acid clusters is plotted using only quantum chemical calculations: in previous studies (Torpo et al., 2007) the size of the clusters limited the data points to two. In this work we have been able to plot a third point on the curve thanks to the new strategy designed.

As can be seen from Fig. 2, the results for the three sets of conditions chosen are qualitatively similar for the sulfuric acid and sulfuric acid - ammonia clusters, so the conclusions for these clusters can be applied to any of the three cases. We can observe that when only two sulfuric acids are present in the cluster, the formation energy is almost the same regardless of whether ammonia is present or not (the differences are between 1.4 and $2.0 \mathrm{kcal} / \mathrm{mol}$ ), but when the number of sulfuric acids increases, the difference between ammonia-containing and ammonia-free clusters becomes evident, reaching a limit between 11.1 and $9.3 \mathrm{kcal} / \mathrm{mol}$ for the clusters with four sulfuric acids. These results confirm that the enhancing effect of ammonia is important for clusters involving more that 2 sulfuric acids, and that ammonia plays an important role in lowering the nucleation barrier of sulfuric acid - containing clusters. Both conclusions are in agreement with experiments (Ball et al., 1999; Hanson et al., 2000) and previous theoretical works (Torpo et al., 2007).

In the case of charged clusters, the plot shows that almost in all conditions a local minimum corresponding to the $\left(\mathrm{H}_{2} \mathrm{SO}_{4}\right)_{2} \cdot \mathrm{HSO}_{4}^{-}$and $\left(\mathrm{H}_{2} \mathrm{SO}_{4}\right)_{2} \cdot \mathrm{HSO}_{4}^{-} \cdot \mathrm{NH}_{3}$ clusters is present. The only exception is the $\Delta G_{3}$ plot, where the formation free energy for $\mathrm{H}_{2} \mathrm{SO}_{4} \cdot \mathrm{HSO}_{4}^{-}$and $\left(\mathrm{H}_{2} \mathrm{SO}_{4}\right)_{2} \cdot \mathrm{HSO}_{4}^{-}$ clusters is the same. This minimum $\Delta G$ is lower for clusters containing ammonia. This is the only effect that the presence of ammonia seems to have. The formation energy is higher for charged two-acid [ $n=2]$ clusters containing ammonia than for ones without it, and also the energy difference 
Table 5. Free energies for the addition of one sulfuric acid molecule and one ammonia molecule to various clusters at different temperatures and $1 \mathrm{~atm}$ of pressure.

\begin{tabular}{|c|c|c|c|}
\hline Reaction & $\Delta G(242 \mathrm{~K})$ & $\Delta G(265 \mathrm{~K})$ & $\Delta G(298 \mathrm{~K})$ \\
\hline $\mathrm{H}_{2} \mathrm{SO}_{4}+\mathrm{H}_{2} \mathrm{SO}_{4} \rightarrow\left(\mathrm{H}_{2} \mathrm{SO}_{4}\right)_{2}$ & -10.21 & -9.65 & -8.84 \\
\hline $\mathrm{H}_{2} \mathrm{SO}_{4}+\left(\mathrm{H}_{2} \mathrm{SO}_{4}\right)_{2} \rightarrow\left(\mathrm{H}_{2} \mathrm{SO}_{4}\right)_{3}$ & -4.33 & -2.89 & -0.82 \\
\hline $\mathrm{H}_{2} \mathrm{SO}_{4}+\left(\mathrm{H}_{2} \mathrm{SO}_{4}\right)_{3} \rightarrow\left(\mathrm{H}_{2} \mathrm{SO}_{4}\right)_{4}$ & -10.31 & -9.70 & -8.83 \\
\hline $\mathrm{H}_{2} \mathrm{SO}_{4}+\mathrm{H}_{2} \mathrm{SO}_{4} \cdot \mathrm{NH}_{3} \rightarrow\left(\mathrm{H}_{2} \mathrm{SO}_{4}\right)_{2} \cdot \mathrm{NH}_{3}$ & -16.53 & -15.44 & -13.87 \\
\hline $\mathrm{H}_{2} \mathrm{SO}_{4}+\left(\mathrm{H}_{2} \mathrm{SO}_{4}\right)_{2} \cdot \mathrm{NH}_{3} \rightarrow\left(\mathrm{H}_{2} \mathrm{SO}_{4}\right)_{3} \cdot \mathrm{NH}_{3}$ & -11.26 & -10.30 & -8.92 \\
\hline $\mathrm{H}_{2} \mathrm{SO}_{4}+\left(\mathrm{H}_{2} \mathrm{SO}_{4}\right)_{3} \cdot \mathrm{NH}_{3} \rightarrow\left(\mathrm{H}_{2} \mathrm{SO}_{4}\right)_{4} \cdot \mathrm{NH}_{3}$ & -11.57 & -11.40 & -11.16 \\
\hline $\mathrm{H}_{2} \mathrm{SO}_{4}+\mathrm{HSO}_{4}^{-} \rightarrow \mathrm{H}_{2} \mathrm{SO}_{4} \cdot \mathrm{HSO}_{4}^{-}$ & -37.26 & -36.14 & -34.52 \\
\hline $\mathrm{H}_{2} \mathrm{SO}_{4}+\mathrm{H}_{2} \mathrm{SO}_{4} \cdot \mathrm{HSO}_{4}^{-} \rightarrow\left(\mathrm{H}_{2} \mathrm{SO}_{4}\right)_{2} \cdot \mathrm{HSO}_{4}^{-}$ & -19.81 & -19.15 & -18.19 \\
\hline $\mathrm{H}_{2} \mathrm{SO}_{4}+\left(\mathrm{H}_{2} \mathrm{SO}_{4}\right)_{2} \cdot \mathrm{HSO}_{4}^{-} \rightarrow\left(\mathrm{H}_{2} \mathrm{SO}_{4}\right)_{3} \cdot \mathrm{HSO}_{4}^{-}$ & -10.71 & -7.86 & -7.34 \\
\hline $\mathrm{H}_{2} \mathrm{SO}_{4}+\mathrm{HSO}_{4}^{-} \cdot \mathrm{NH}_{3} \rightarrow \mathrm{H}_{2} \mathrm{SO}_{4} \cdot \mathrm{HSO}_{4}^{-} \cdot \mathrm{NH}_{3}^{-}$ & -38.70 & -37.63 & -36.09 \\
\hline $\mathrm{H}_{2} \mathrm{SO}_{4}+\mathrm{H}_{2} \mathrm{SO}_{4}^{-} \cdot \mathrm{HSO}_{4}^{-} \cdot \mathrm{NH}_{3} \rightarrow\left(\mathrm{H}_{2} \mathrm{SO}_{4}^{+}\right)_{2} \cdot \mathrm{HSO}_{4}^{-} \cdot \mathrm{NH}_{3}$ & -34.39 & -34.01 & -33.47 \\
\hline $\mathrm{H}_{2} \mathrm{SO}_{4}+\left(\mathrm{H}_{2} \mathrm{SO}_{4}\right)_{2} \cdot \mathrm{HSO}_{4}^{-} \cdot \mathrm{NH}_{3} \rightarrow\left(\mathrm{H}_{2} \mathrm{SO}_{4}\right)_{3} \cdot \mathrm{HSO}_{4}^{-} \cdot \mathrm{NH}_{3}$ & -7.80 & -6.11 & -3.68 \\
\hline $\mathrm{H}_{2} \mathrm{SO}_{4}+\mathrm{NH}_{3} \rightarrow \mathrm{H}_{2} \mathrm{SO}_{4} \cdot \mathrm{NH}_{3}$ & -7.14 & -6.38 & -5.27 \\
\hline$\left(\mathrm{H}_{2} \mathrm{SO}_{4}\right)_{2}+\mathrm{NH}_{3} \rightarrow\left(\mathrm{H}_{2} \mathrm{SO}_{4}\right)_{2} \cdot \mathrm{NH}_{3}$ & -13.46 & -12.17 & -10.31 \\
\hline$\left(\mathrm{H}_{2} \mathrm{SO}_{4}\right)_{3}+\mathrm{NH}_{3} \rightarrow\left(\mathrm{H}_{2} \mathrm{SO}_{4}\right)_{3} \cdot \mathrm{NH}_{3}$ & -20.38 & -19.58 & -18.41 \\
\hline$\left(\mathrm{H}_{2} \mathrm{SO}_{4}\right)_{4}+\mathrm{NH}_{3} \rightarrow\left(\mathrm{H}_{2} \mathrm{SO}_{4}\right)_{4} \cdot \mathrm{NH}_{3}$ & -22.38 & -22.01 & -21.49 \\
\hline $\mathrm{HSO}_{4}^{-}+\mathrm{NH}_{3} \rightarrow \mathrm{HSO}_{4}^{-} \cdot \mathrm{NH}_{3}$ & 1.02 & 1.86 & 3.04 \\
\hline $\mathrm{H}_{2} \mathrm{SO}_{4}^{4} \cdot \mathrm{HSO}_{4}^{-}+\mathrm{NH}_{3} \rightarrow \mathrm{H}_{2} \mathrm{SO}_{4} \cdot \mathrm{HSO}_{4}^{-} \cdot \mathrm{NH}_{3}$ & 5.21 & 3.46 & 7.10 \\
\hline$\left(\mathrm{H}_{2} \mathrm{SO}_{4}\right)_{2} \cdot \mathrm{HSO}_{4}^{-}+\mathrm{NH}_{3} \rightarrow\left(\mathrm{H}_{2} \mathrm{SO}_{4}\right)_{2} \cdot \mathrm{HSO}_{4}^{-} \cdot \mathrm{NH}_{3}$ & -14.99 & -14.51 & -13.81 \\
\hline$\left(\mathrm{H}_{2} \mathrm{SO}_{4}\right)_{3} \cdot \mathrm{HSO}_{4}^{-}+\mathrm{NH}_{3} \rightarrow\left(\mathrm{H}_{2} \mathrm{SO}_{4}\right)_{3} \cdot \mathrm{HSO}_{4}^{-} \cdot \mathrm{NH}_{3}$ & -12.08 & -13.27 & -9.63 \\
\hline
\end{tabular}

between charged three $[n=3]$ - and four $[n=4]$-acid clusters is larger when ammonia is present. We can conclude that ammonia does not enhance the growth of charged clusters. Furthermore, the stabilization of the local minimum may actually increase the nucleation barrier for ionic clusters containing ammonia.

To get an estimation of how the nucleation barrier changes with temperature for the charged clusters we have calculated $\Delta G$ curves for the hydrogensulfate ion clusters at lower temperatures. In Fig. 3 we have plotted the energy difference between four and three sulfuric acid clusters versus the temperature. We can see that the energy difference between the clusters decreases quickly with the temperature, vanishing at $200 \mathrm{~K}$. This indicates that at high altitude conditions, where the temperature falls bellow $240 \mathrm{~K}$ and the concentration of ions is high, ion induced nucleation is a barrierless process. This agrees with previous works (lee et al., 2003, Lovejoy et al., 2004), and confirms the important role that ion nucleation plays in new particle formation in the upper troposphere and lower stratosphere. On the other hand, when we move toward ground level conditions $\left(\Delta G_{3}\right)$, this barrier grows, and probably plays a role in determining nucleation rates. In field measurements carried out by Eisele et al. (2006) at ground level, a large amount of $\left(\mathrm{H}_{2} \mathrm{SO}_{4}\right)_{2} \cdot \mathrm{HSO}_{4}^{-}$was detected, but no larger ionic cluster could be found: the authors thus concluded that ion induced nucleation does not play an important role in particle formation at those conditions. These observations are in agreement with our results that at representative ground-level conditions, ion induced nucleation is not a barrierless process, so the clusters grow to a local minimum and then prefer to stay there rather than grow further. This can explain the large concentration of $\left(\mathrm{H}_{2} \mathrm{SO}_{4}\right)_{2} \cdot \mathrm{HSO}_{4}^{-}$clusters found in the experimental study (Eisele et al., 2006), since in our calculation that cluster is predicted to correspond to the local minimum in the $\Delta G$ curve.

To understand the thermochemistry further, we also calculate the reaction free energies for the addition of one sulfuric acid molecule and of one ammonia molecule to the clusters. These energies at three different temperatures are listed in Table 5. All values correspond to reactions involving the most stable clusters at each temperature. The sulfuric acid addition energy is significantly lower when ammonia is present in the cluster for 1- and 2-acid clusters, but the difference is smaller for the addition of a fourth sulfuric acid. This probably indicates that the presence of a second molecule of ammonia would lower this addition energy, allowing the cluster grow to larger sizes. In other words, clusters with four sulfuric acid molecules will probably, more than 1 ammonia molecule in atmospheric conditions. This agrees with the ammonia-sulfuric acid ratio (between 1:1 and 1:3) predicted in the atmosphere by previous studies (Kurtén et al., 2007c).

For one hydrogensulfate ion clusters, we can see how the addition energy of sulfuric acid is very similar with and without ammonia. The difference becomes important when one sulfuric acid is already present in the cluster, and we can see that the presence of ammonia clearly favors the addition of 
a second sulfuric acid molecule to the cluster. For a cluster containing two sulfuric acid molecules and one hydrogensulfate ion, the addition of one more sulfuric acid is more favorable for clusters without ammonia. This confirms our previous conclusion that ammonia does not enhance the growth of ionic sulfuric acid clusters.

The addition of one ammonia molecule to sulfuric acid clusters is more favorable as the cluster size grows. For hydrogensulfate ion cluster, the addiction of ammonia to small clusters is not favorable, having a positive value for $\Delta G$, this is in agreement with previous works (Hanson and Eisele, 2002). On the other hand, when the clusters grow to larger sizes the addition of ammonia becomes favorable, especially for the cluster containing two sulfuric acid and one hydrogensulfate ion, which corresponds to the local minimum in $\Delta G$ curves plotted in Fig. 2.

\section{Conclusions}

We have developed a new multi-step strategy for quantum chemical calculations on atmospherically relevant cluster structures. This strategy has allowed us to perform calculations for clusters containing up to 4 sulfuric acid molecules and one ammonia. We have calculated formation free energies in three different atmospheric conditions, obtaining the free energy curves for each condition and each cluster type studied. This strategy will be very useful in future studies which require calculations on large clusters, or clusters containing large molecules such as various biogenic organic compounds.

Our results confirm the enhancing effect of ammonia on the growth of neutral sulfuric acid clusters. The computed formation free energies curves show that the nucleation barrier for sulfuric acid nucleation is lowered by the presence of ammonia.

Our results show that ammonia does not have any enhancing effect on hydrogensulfate ion induced nucleation. The only remarkable effect of ammonia on the charged clusters is the stabilization of the $\left(\mathrm{H}_{2} \mathrm{SO}_{4}\right)_{2} \cdot \mathrm{HSO}_{4}^{-}$cluster. We have also confirmed that ion induced nucleation is a barrierless process in high altitude conditions while a moderately high barrier exists at ground level conditions, so it will have larger contribution to new particle formation at upper troposphere conditions, but this contribution will be very small at ground level conditions, where other mechanism will have a bigger contribution. The barrier is associated with a local minimum corresponding to the $\left(\mathrm{H}_{2} \mathrm{SO}_{4}\right)_{2} \cdot \mathrm{HSO}_{4}^{-}$cluster. This explains why high concentrations of $\left(\mathrm{H}_{2} \mathrm{SO}_{4}\right)_{2} \cdot \mathrm{HSO}_{4}^{-}$clusters, but not larger charged clusters, were found in field measurements carried out at ground level (Eisele at al., 2006).
Acknowledgements. The authors thank the Scientific Computing Center (CSC) in Espoo, Finland for the computing time, and the Academy of Finland and Emil Aaltonen foundation for financial support.

Edited by: A. Wiedensohler

\section{References}

Ahlrichs, R., Bär, M., Häser, J., Horn, H., and Kölmel, C.: Electronic structure calculations on workstation computers: the program system TURBOMOLE, Chem. Phys. Lett., 162, 165-169, 1989.

Anttila, T., Vehkamaki, H., Napari, I., and Kulmala, M.: Effect of ammonium bisulphate formation on atmospheric water-sulphuric acid-ammonia nucleation, Boreal Env. Res., 10, 511-523, 2005

Ball, S. M., Hanson, D. R., Eisele, F. L., and McMurry, P. H.: Laboratory studies of particle nucleation: Initial results for $\mathrm{H}_{2} \mathrm{SO}_{4}$, $\mathrm{H}_{2} \mathrm{O}$, and $\mathrm{NH}_{3}$ vapors, J. Geophys. Res. D, 104, 23 709-23 718, 1999.

Du, H., Yu, F., and Nadykto, A.: Water homogeneous nucleation: Importance of clustering thermodynamics in: Proceedings of the $17^{\text {th }}$ International conference on nucleation and atmospheric aerosols, Galway, Ireland, 13-17 August 2007, 167-171, 2007.

Dunning Jr., T. H., Peterson, K. A., and Wilson, A. K.: Gaussian basis sets for use in correlated molecular calculations. X. The atoms aluminum through argon revisited, J. Chem. Phys., 114, 9244-9253, 2001.

Eisele, F. L., Lovejoy, E. R., Kosciuch, E., Moore, K. F., Mauldin III, R. L., Smith, J. N., McMurry, P. H. and Iida K.: Negative atmospheric ions and their potential role in ion-induced nucleation, J. Gephys. Res., 111, D04305, doi:10.1029/2005JD006568, 2006.

Hanson, D. R. and Eisele, F. L.: Diffusion of $\mathrm{H}_{2} \mathrm{SO}_{4}$ in humidified nitrogen: Hydrated $\mathrm{H}_{2} \mathrm{SO}_{4}$, J. Phys. Chem. A, 104, 1715-1719, 2000.

Hanson, D. R. and Eisele, F. L.: Measurement of prenucleation molecular clusters in the $\mathrm{NH}_{3}, \mathrm{H}_{2} \mathrm{SO}_{4}, \mathrm{H}_{2} \mathrm{O}$ system, J. Geophys. Res., 107, 4158-4166, 2002.

Hättig, C. and Weigend, F.: CC2 excitation energy calculations on large molecules using the resolution of the identity approximation, J. Chem. Phys., 113, 5154-5161, 2000.

Ianni, J. C. and Bandy, A. R.: A Density functional theory study of the hydrates of $\mathrm{NH}_{3} \cdot \mathrm{H}_{2} \mathrm{O} \cdot \mathrm{H}_{2} \mathrm{SO}_{4}$ and its implications for the formation of new atmospheric particles, J. Phys. Chem. A, 103, 2801-2811, 1999.

Jensen F.: Introduction to computational chemistry, John Wiley \& Sons, West Sussex, England, 1998.

Kathmann, S., Schenter, G., and Garret, B.: The critical role of anharmonicity in aqueous ionic clusters relevant to nucleation, J. Phys. Chem. C, 111, 4977-4983, 2007.

Kulmala, M., Pirjola, L., and Mäkelä, J. M.: Stable sulphate clusters as a source of new atmospheric particles, Nature, 404, 66-69, 2000.

Kulmala, M.: How particles nucleate and grow, Science 302, 10001001, 2003.

Kulmala, M., Vehkamäki, H., Petäjä, T., Dal Maso, M., Lauri, A., Kerminen V. M., Birmili, W., and McMurry, P. H.: Formation 
and growth rates of ultrafine atmospheric particles: a review of observations, J. Aerosol. Sci., 35, 143-176, 2004.

Kulmala, M., Lehtinen, K. E. J., and Laaksonen A.: Cluster activation theory as an explanation of the linear dependence between formation rate of $3 \mathrm{~nm}$ particles and sulphuric acid concentration, Atmos. Chem. Phys. 6, 787-793, 2006.

Kulmala, M., Riipinen, I., Sipilä, M., Manninen, H: E., Petäjä, T., Junninen, H., Dal Maso, M., Mordas, G., Mirme, A., Vana, M., Hirsikko, A., Laakso, L., Harrison, R. M., Hanson, I., Leung, C., Lehtinen, K. E. J. and Kerminen V. M.: Toward direct measurement of atmospheric nucleation, Science, 318, 89-92, doi:10.1126/science.1144124, 2007.

Kurtén, T., Noppel, M., Vehkamaki, H., Salonen, M., and Kulmala, M.: Quantum chemical studies of hydrate formation of $\mathrm{H}_{2} \mathrm{SO}_{4}$ and $\mathrm{HSO}_{4}^{-}$, Boreal Env. Res., 12, 431-453, 2007a.

Kurtén, T., Torpo, L., Ding, C. G., Vehkamaki, H., Sundberg, M. R., Laasonen, K., and Kulmala, M.: A density functional study on water-sulfuric acid-ammonia clusters and implications for atmospheric cluster formation, J. Geophys. Res., 112, D04210, doi:10.1029/2005JD006568, 2007b.

Kurtén, T., Torpo, L., Sundberg, M. R., Kerminen, V. M., Vehkamaki, H., and Kulmala, M.: Estimating the $\mathrm{NH}_{3}: \mathrm{H}_{2} \mathrm{SO}_{4}$ ratio of nucleating clusters in atmospheric conditions using quantum chemical methods, Atmos. Chem. Phys., 7, 2765-2773, 2007c, http://www.atmos-chem-phys.net/7/2765/2007/.

Laakso, L., Gagné, S., Petäjä, T., Hirsikko, A., Aalto, P. P., Kulmala, M., and Kerminen, V.-M.: Detecting charging state of ultra-fine particles: instrumental development and ambient measurements, Atmos. Chem. Phys., 7, 1333-1345, 2007, http://www.atmos-chem-phys.net/7/1333/2007/.

Lee, S. H., Reeves, J. M., Wilson, J. C., Hunton, D. E., Viggiano, A. A., Miller, T. M., Ballenthin, J. O., and Lait, L. R.: Particle formation by ion nucleation in the upper troposphere and lower stratosphere, Science, 301, 1886-1889, 2003.

Lovejoy, E. R., Curtius, J. and Froyd, K. D.: Atmospheric ioninduced nucleation of sulfuric acid and water, J. Geophys. Res., 109, D08204, doi:10.1029/2003JD004460, 2004.

Miehlich, B., Savin, A., Stoll, H., and Preuss, H.: Results obtained with the correlation-energy density functionals of Becke and Lee, Yang and Parr, Chem. Phys. Lett., 157, 200-206, 1989.
Nadykto, A. B. and Yu, F.: Strong hydrogen bonding between atmospheric nucleation precursors and common organics, Chem. Phys. Lett., 435, 14-18, 2007.

Riipinen, I., Sihto, S.-L., Kulmala, M., Arnold, F., Dal Maso, M., Birmili, W., Saarnio, K., Teinilä, K., Kerminen, V.-M., Laaksonen, A., and Lehtinen, K. E. J.; Connections between atmospheric sulphuric acid and new particle formation during QUEST III - IV campaigns in Hyytiälä and Heidelberg. Atmos. Chem. Phys., 7, 1899-1914, 2007, http://www.atmos-chem-phys.net/7/1899/2007/.

Schaftenaar, G. and Noordik, J. H.: MOLDEN: a pre- and postprocessing program for molecular and electronic structures, J. Comput.-Aided Mol. Design, 14, 123-134, 2000.

Sihto, S.-L., Kulmala, M., Kerminen, V.-M., Dal Maso, M., Petäjä, T., Riipinen, I., Korhonen, H., Arnold, F., Janson, R., Boy, M., Laaksonen, A., and Lehtinen, K. E. J: Atmospheric sulphuric acid and aerosol formation: implications from atmospheric measurements for nucleation and early growth mechanisms. Atmos. Chem. Phys., 6, 4079-4091, 2006, http://www.atmos-chem-phys.net/6/4079/2006/.

Soler, J. M., Artacho, E., Gale, J. D., Garcia, A., Junquera, J., Ordejon, P., and Sanchez-Portal, D.: The SIESTA method for ab initio order-N materials simulation, J. Phys-Condens. Mat., 14, 2745-2779, 2002.

Torpo, E., Kurtén, T., Vehkamäki, H., Laasonen, K., Sundberg, K., and Kulmala, M.: Significance of ammonia in growth of atmospheric nanoclusters, J. Phys. Chem A, 111, 10 671-10 674, 2007

Wavefunction, Inc: Spartan '06 Windows, Wave function, Inc. Irvine, CA, USA, http://wavefun.com, 2006

Weber, R. J., Marti, J. J., McMurry, P. H., Eisele, F. L., Tanner, D. J., and Jefferson, A.: Measured atmospheric new particle formation rates: Implications for nucleation mechanisms, Chem. Eng. Commun., 151, 53-64, 1996

Weber, R. J., Marti, J. J., McMurry, P. H., Eisele, F. L., Tanner, D. J., and Jefferson, A.: Measurements of new particle formation and ultrafine particle growth rates at a clean continental site, J. Geophys. Res., 102(D4), 4375-4385, 1997 